\title{
Effects of Cryofrequency in the Different Swine Skin Tissue Layers: In Vitro and in Vivo Study
}

\author{
Rafaella Rêgo Maia1, Patrícia Froes Meyer ${ }^{1,2 *}$, Josebel da Costa Emerenciano ${ }^{3}$, \\ Joseela Joyce Barbosa da Silva ${ }^{3}$, Júlio Davi Costa e Silva ${ }^{3}$, Liliane Santos de Vasconcellos ${ }^{1}$, \\ Rodrigo Marcel Valentim da Silva1,4, Tarciso Bruno Montenegro Sampaio ${ }^{3}$, Ciro Dantas Soares ${ }^{5}$
}

${ }^{1}$ Federal Universityof Rio Grande do Norte (UFRN), Natal, Brazil

${ }^{2}$ University Centre of Rio Grande do Norte (UNI-RN), Natal, Brazil

${ }^{3}$ Potiguar University (UNP), Natal, Brazil

${ }^{4}$ Maurício de Nassau College, Natal, Brazil

${ }^{5}$ Universityof Campinas (UNICAMP), São Paulo, Brazil

Email: ${ }^{\star}$ patricia.froesmeyer@gmail.com

How to cite this paper: Maia, R.R., Meyer, P.F., da Costa Emerenciano, J., da Silva, J.J.B., e Silva, J.D.C., de Vasconcellos, L.S., da Silva, R.M.V., Sampaio, T.B.M. and Soares, C.D. (2021) Effects of Cryofrequency in the Different Swine Skin Tissue Layers: In Vitro and in Vivo Study. Journal of Biosciences and Medicines, 9, 94-104. https://doi.org/10.4236/jbm.2021.93010

Received: February 18, 2021

Accepted: March 26, 2021

Published: March 29, 2021

Copyright $\odot 2021$ by author(s) and Scientific Research Publishing Inc. This work is licensed under the Creative Commons Attribution International License (CC BY 4.0).

http://creativecommons.org/licenses/by/4.0/

\begin{abstract}
Introduction: Cryofrequency is a novel therapy which was developed with the combination of cold (cryotherapy) and heat (radiofrequency) application, causing a thermal shock effect on skin tissue. The thermal shock is believed to alter local metabolism. Objective: To investigate the effect of cryofrequency on the skin tissue of a mini pig in an in vitro and in vivo experimental model. Methodology: A small swine of the $S$. domesticus species, a male mini-pig (30 kg weight) was elected for the in vivo procedure subject. The in vitro step was performed on the extracted abdominal part of another subject of the same species and breed. Then, after the application of cryofrequency in the monopolar and bipolar form in vivo, a histological analysis was performed. Results: A higher temperature variation was observed comparing the pilot study in vitro with respect to the experimental one in vivo. Microscopically, an increase of collagen fibers and blood supply and decreased adipose tissue was observed after cryofrequency application. Conclusion: With the bipolar cryofrequency, no reduction of adipose tissue was observed, but regarding the connective tissue, extensive areas of collagen deposition were observed, as well as a great amount of new-formed collagen fibers.
\end{abstract}

\section{Keywords}

Cryotherapy, Radio Frequency, Adiposity, Collagen, Temperature

\section{Introduction}

The localized adiposity is characterized by an excessive fat accumulation in dif- 
ferent regions of the human body [1]. Although the body relies on normal levels of fat for the satisfactory performance of its metabolic activities, its excess, even locally, may be detrimental due to the probable increase in serum levels of LDL and triglyceride fractions, which contribute to the development of cardiovascular disorders [2]. This condition presents itself differently in each individual, depending on genetic and hormonal factors [3].

The classic treatments for localized adiposity are surgical interventions and diets, associated with physical exercises. To assist in the non-invasive reduction of the localized fat layer, some therapeutic techniques have been proposed, such as electrolypolysis, ultracavitation, cryolipolysis, and radiofrequency (RF). The radiofrequency consists of electromagnetic waves from $30 \mathrm{KHz}$ to $300 \mathrm{MHz}$, which generate heat per conversion. The most commonly used frequency is between 0.5 and $1.5 \mathrm{MHz}$ [4] [5] [6] [7].

The thermal effects of RF promote collagen denaturation, with immediate contraction of its fibers and subsequent fibroblasts activation with replacement of the collagen fibers over time (neocollagenesis), due to a secondary healing response and subsequent cutaneous tissue remodeling. The contraction of tissues with temperature occurs immediately after it reaches threshold temperature [8] [9].

A novel radiofrequency modality called cryofrequency is being proposed today. The difference between radiofrequency and cryofrequency devices is that the second brings two associated technologies in its applicator: the radiofrequency and the cryotherapy, with cold thermo-inducers reaching as low as $-10^{\circ} \mathrm{C}$, bringing thermal shock to the tissue. The energy released from this electrode leads to better circulatory and nutrient supply, tissue hydration, increased oxygenation, acceleration of the catabolitese limination, lipolysis, connective tissue contraction and consequent collagen fibers contraction, whilst improving the skin architecture changes without causing the surface tissue to feel the temperature increase [4] [8].

Although these effects on dermal and hypodermic tissue, including adipose tissue apoptosis, are attributed to cryofrequency, when this study was carried out, there was no other research that demonstrated its mechanism of action or even showed the temperatures reached in the dermal and hypodermic tissue with the use of this technology. This study is a pioneer in the research of this technology. The available information is found in equipment manuals [10], which describe the possibility of reaching temperatures as low as $-10^{\circ} \mathrm{C}$ on the skin surface while deeper tissue layers reach $50^{\circ} \mathrm{C}$ or more.

Therefore, in view of the presence of this technology in the routine of aesthetic treatments and the lack of specialized literature in this regard, the purpose of this study was to analyze the effects of cryofrequency in the different tissues of swine skin, through in vitro and in vivo analyzes, aiming at clarifying whether the combination of cryotherapy and radiofrequency techniques are advantageous in the treatment of adipose tissue and tissue flaccidity. 


\section{Methodology}

This experimental preclinical test was performed using in vitro and in vivo specimens/ subjects. This test type is more often used as it corroborates with the social pressure in favor of alternative testing models, with the purpose of reducing the number of animals used in research and development of innovative technologies.

This project was submitted and approved within the Ethics Committee for the Use of Animals (CEUA) of the Potiguar University (UNP), under registration number 022/2017.

The sample subject was a small swine of the $S$. domesticus species, Suidae Family, a 30-kg-male individual of the breed named "Mini Pig". The animal was bred at "Rancho Micropig", in the city of São Roque/SP, Brazil, for the surgical practices laboratory, where it remained for 7 days, for adaptation purposes, under air-conditioning controlled environment.

The instruments used in this research were: a syringe; a needle; procedure gloves; a scalpel; a sterile surgery field; ADOXY MEDICAL ${ }^{\mathrm{TM}}$ brand of anti-fouling device; alcohol 70\% gel; digital camera; thermal imaging camera (FLIR $\mathrm{C} 2$ ); non-contact infrared thermometer (TECHLINE); digital probe thermometer; simple rule of $15 \mathrm{~cm}$; Olympus optical microscope.

\subsection{In Vitro Procedures}

The research started with the pilot study in vitro. It was necessary to evaluate the in vitro temperature first, due to lack of literature data regarding temperature, or how much power to apply, and even what happens to the innermost skin layers in response to heating. The sample was a piece of flesh from the swine's abdominal region, obtained in its fresh state at a street fair in the city of Macaíba/RN Brazil. The sample was placed on an insulation material and at room temperature. Cryofrequency was applied with the monopolar and bipolar heads for 8 minutes each application, and the temperature checked each minute with the following devices (Figure 1): a thermographic camera, a contact-free infrared thermometer, a digital probe thermometer (with the use of gel), and a ruler for area delimitation.

\subsection{In Vivo Procedures}

In the in vivo experimental procedure, a mini pig was used as the experimental
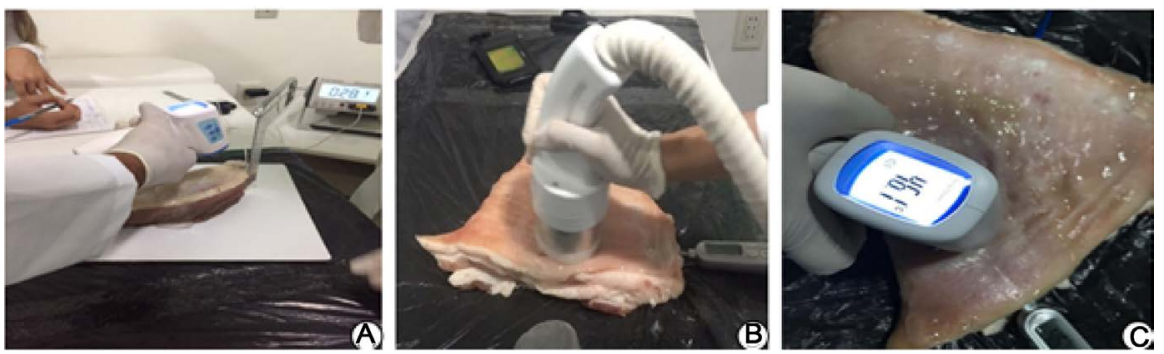

Figure 1. Procedures in vitro, abdominal part of the animal. 
model and the collection lasted one day. The procedure started with the animal being weighed and then anesthetized with Tiletamine hydrochloride and Zolazepam hydrochloride (Zoletil ${ }^{\mathrm{TM}} 50$ ). The solution was administered by a veterinarian according to its weight. The area was marked; the dorsum and abdomen were manually trycotomized, and then the antisepsis was performed with aqueous antiseptic chlorhexidine.

The protocol on the animal's abdomen started with the use of ADOXYMEDI$\mathrm{CA}^{\mathrm{TM}}$, Andrus model (Curitiba/PR, Brazil), with the different monopolar heads (Figure 2(A)) and bipolar on the animal's back (Figure 2(B)), using a power of $450 \mathrm{~W}$ parameter available in a CRF manual and the manufacturer's suggestions.

The animal was monitored for vital signs and systemic temperature throughout the procedure (Figure $2(\mathrm{C})$ ). After $48 \mathrm{~h}$, the procedures of lethal injection euthanasia were carried out. Fragments of the animal tissue were removed for histological study from the areas corresponding to the application (Figures 2(D)-(F)) and from areas which did not receive application (back and abdomen, respectively).

\subsection{Data Analysis}

The biological fragments were fixed with formaldehyde at $10 \%$ in the Laboratory of Surgical Practices of the Potiguar University (UNP), and kept in the substance for $24 \mathrm{~h}$ for fixation.

The piece was dehydrated in alcohol three times, one hour each, diaphanized with 3 baths of Xylol ${ }^{\mathrm{TM}}$ for 10 minutes each. The inclusion process was started by immersing the biological tissue in paraffin heated at $65^{\circ} \mathrm{C}$ in three for three periods of $1 \mathrm{~h}$ each. After paraffin hardening, the fragment proceeded to the microtome and cut into 5 - $\mu$ m-thick sections. Hematoxylin and Eosin (HE) and

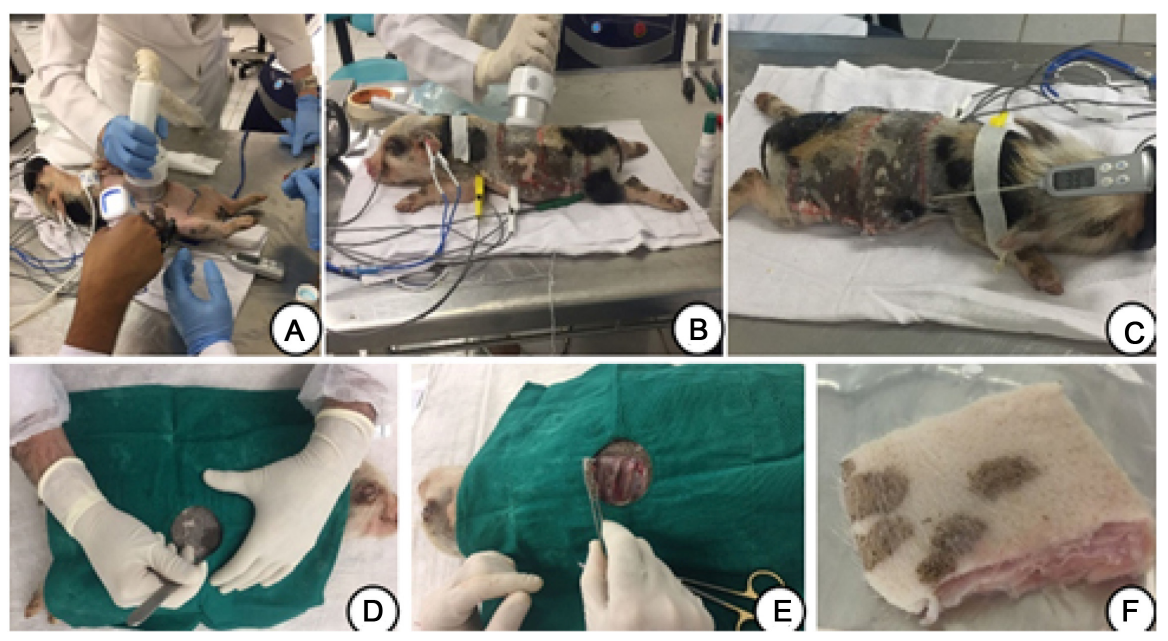

Figure 2. In vivo procedures. (A): Application of cryofrequency in the abdomen of the animal. (B): Application of cryofrequency on the animal's back. (C): Animal being monitored vital signs and systemic temperature. (D): Collection of biological material. (E): Collection of biological material. (F): Collection of biological material. 
Masson's trichrome stainings were used for the histopathological study.

The slides were blindly examined by two pathologists who used an Olympus optical microscope and microphotographs obtained with a microscope-coupled digital camera, which evidenced the effect of the treatment with changes to different tissues such as the dermal and the hypodermic tissue.

\section{Results}

\subsection{Temperature Analysis in Vitro and in Vivo}

Table 1 presents the results of the temperature evaluations in the pilot study in vitro and in the in vivo experiment, with monopolar radiofrequency, bipolar radiofrequency, monopolar cryofrequency, and bipolar cryofrequency. The temperatures presented were measured before timing (minute zero), and at the $8^{\text {th }}$ minute, in the depths of $0.5 \mathrm{~cm}, 1 \mathrm{~cm}, 2 \mathrm{~cm}$ and $3 \mathrm{~cm}$.

The graphs above show two in vitro (left) and in vivo (right), minimum and maximum temperatures, minimum depth $(0.5 \mathrm{~cm}$, Figure 3$)$ and maximum depth (3 cm, 0 minute), and maximum ( 8 minutes, Figure 4 ) for each device (monopolar radiofrequency, bipolar radiofrequency, monopolar cryofrequency, and bipolar cryofrequency).

Table 1. Results of the in vitro and in vivo pilot study, from minutes 0 to minute 8 , depth $0.5 \mathrm{~cm}, 1 \mathrm{~cm}, 2 \mathrm{~cm}, 3 \mathrm{~cm}$.

\begin{tabular}{cccccc}
\hline Modality & Stydy Type & $\mathbf{0 . 5} \mathbf{c m}$ & $1.0 \mathrm{~cm}$ & $\mathbf{2 . 0} \mathbf{c m}$ & $3.0 \mathrm{~cm}$ \\
\hline \multirow{2}{*}{ RF monopolar } & in vitro & $22-41$ & $17-40$ & $16-36$ & $15.3-39.5$ \\
& in vivo & $29-43.2$ & $25-40.5$ & $24-39.9$ & $22-40.9$ \\
RF bipolar & in vitro & $19-53$ & $18.5-36$ & $16-26$ & $15.5-22$ \\
& in vivo & $30-48$ & $27-43.6$ & $25.2-42.6$ & $24-37.6$ \\
Cryo monopolar & in vitro & $19-10$ & $18-23$ & $16-28$ & $15-37$ \\
& in vivo & $28-13$ & $28-19.8$ & $26-27.6$ & $24-39.1$ \\
Cryo Bipolar & in vitro & $19-12$ & $16-26.6$ & $14-22$ & $19-20.6$ \\
& in vivo & $29-20$ & $30-27$ & $25.8-37.4$ & $24-38.7$ \\
\hline
\end{tabular}

TEMPERATURE $\left({ }^{\circ} \mathrm{C}\right)-0.5 \mathrm{CM}$

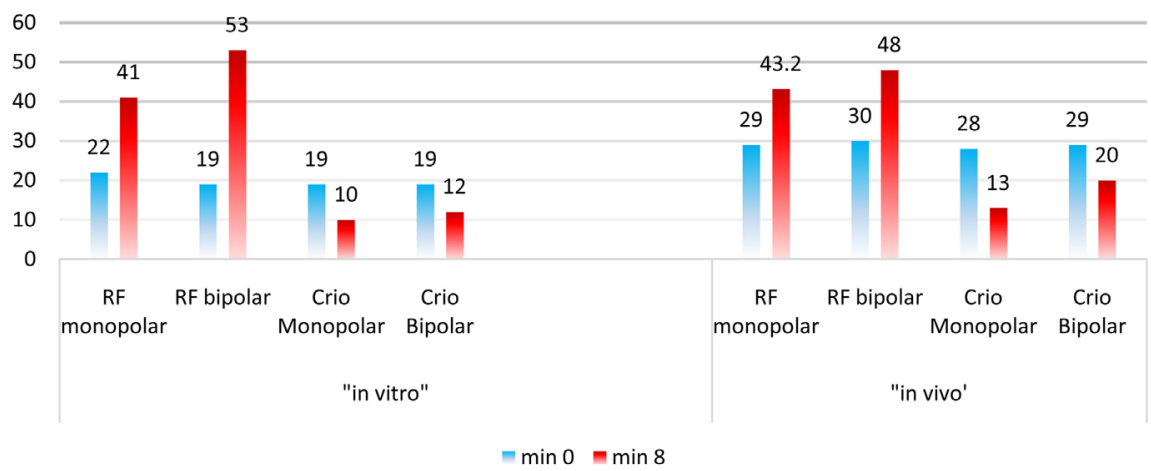

Figure 3. Temperatures at minute 0 and at minute 8 , in the in vitro and in vivo experiments, in the monopolar and bipolar radiofrequency modalities and monopolar and bipolar cryofrequency at $0.5 \mathrm{~cm}$ depth. 
TEMPERATURE $\left({ }^{\circ} \mathrm{C}\right)-3 \mathrm{CM}$

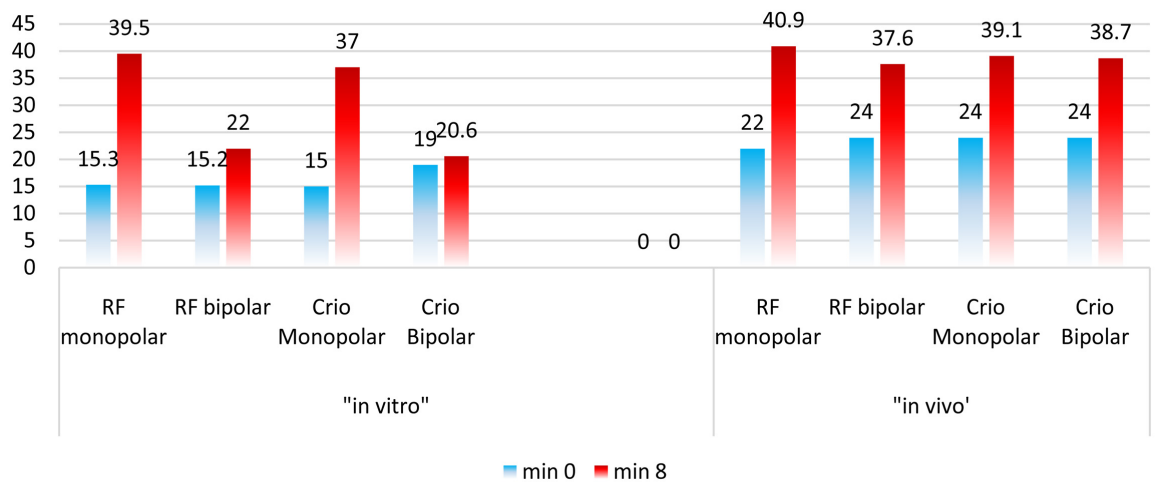

Figure 4. Temperatures at minute 0 and at minute 8 , in the in vitro and in vivo experiments, in the monopolar and bipolar radiofrequency modalities and monopolar and bipolar cryofrequency at $3 \mathrm{~cm}$ depth.

Histologically, it was observed changes in adipose tissue, such as its reduction, an inflammatory process, presence of collagen fibers. With radiofrequency and cryofrequency application with the monopolar head, the skin of the abdominal region presented reduction of adipose tissue, greater presence of blood vessels, and fibroblasts (Figure 5(B)), when compared to control non-treated skin (Figure $5(\mathrm{~A})$ ), signaling greater inflammatory process in the treated skin. In the application of radiofrequency and cryofrequency with the bipolar head in the dorsal region of the animal there was no alteration regarding the adipose tissue compared to the same control areas.

\subsection{Histological Analysis Regarding the Collagenous Tissue}

Cellular proliferation was higher in the skin treated with monopolar cryofrequency compared to the monopolar radiofrequency treatment. Monopolar radiofrequency with cryofrequency reached greater depths of dermal tissue and, consequently, the adipose tissue was more affected.

The control skin (Figure 5(A)) shows the normal dermis thickness, with sparse and morphologically normal collagen fibers. The skin that received the application of monopolar cryofrequency (Figure 5(B)) of 450w for 8 minutes, presented a compact organization of the collagen fibers and higher fiber density.

With the monopolar cryofrequency, a large number of new-formed collagen fibers were present in the superficial and deep dermis (Figure 6(A)), and fibroblasts were identified in the deep dermis, demonstrating an increase in the number of cells in this area, with very evident neocollagenesis along the skin (Figure 6(B)).

In the comparative analysis between the skin treated with bipolar RF and the bipolar cryofrequency, there is collagen stimulation in the superficial dermis in both, but there was higher neocollanogenesis in the cryofrequency-treated skin. In the application of bipolar radiofrequency, a slight deposition of fibers in the dermo-epidermal junction area may be observed (Figure $7(\mathrm{~A})$ ), and a more 


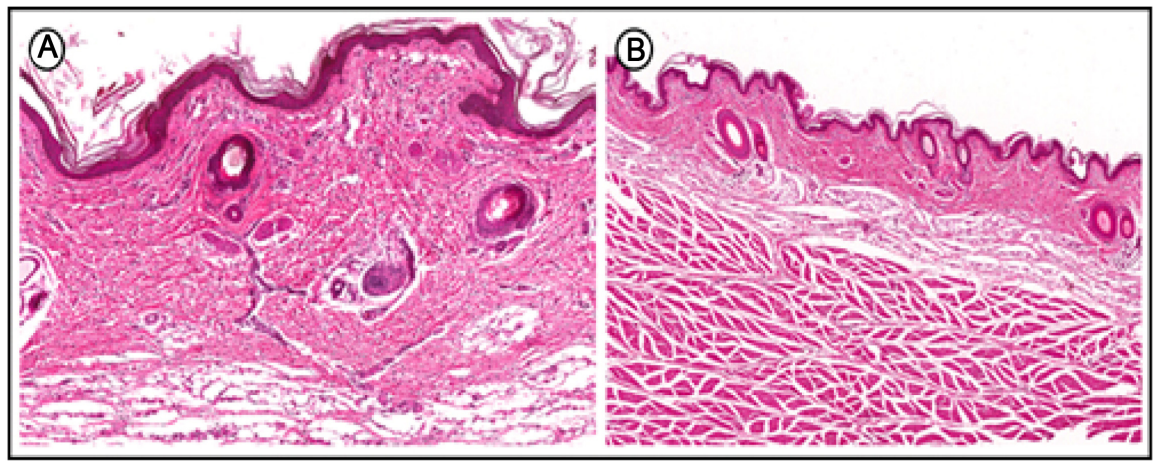

Figure 5. Collagen and adipose tissue; effects of monopolar cryofrequency; (A): Control group, normal adipose tissue. (B): Monopolar cryofrequency group, reduction of the layer of adipose tissue.

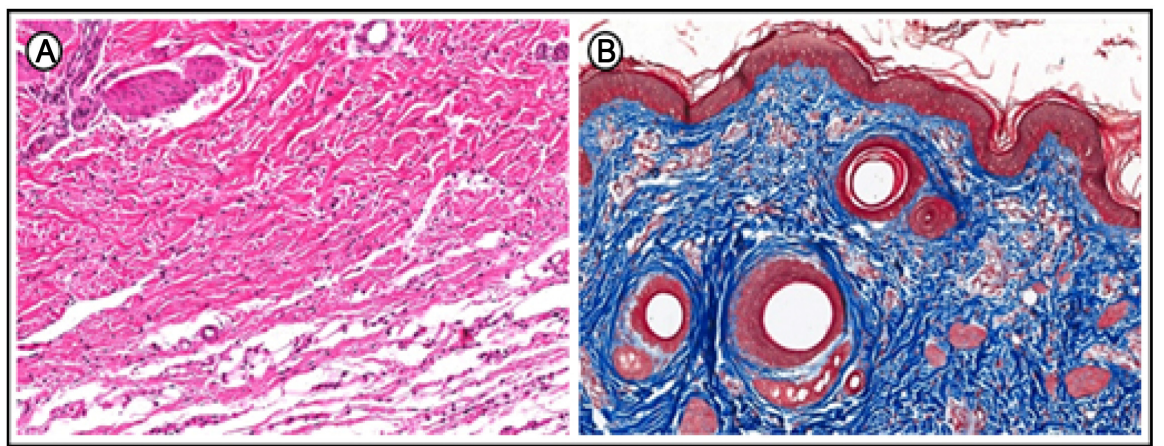

Figure 6. Comparison in relation to collagen; effects of monopolar cryofrequency. (A): Newformed collagen fibers. (B): Neocollagenesis.

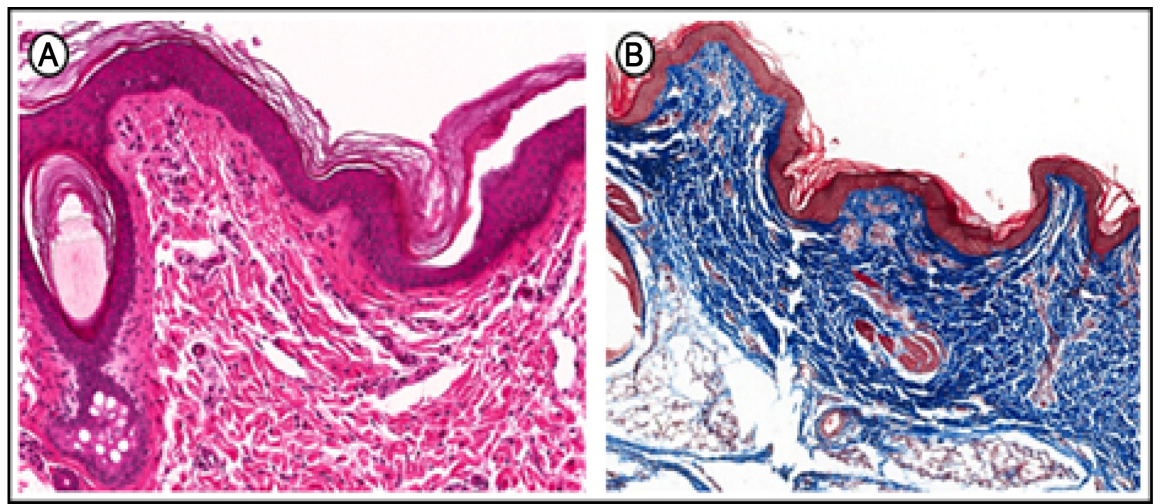

Figure 7. Bipolar radiofrequency regarding collagen. (A): Deposition of fibers in the dermoepidermal junction area. (B): Neocollagenesis.

compact distribution of the collagen fibers is also clear, which indicates neocollagenesis (Figure 7(B)).

The results with the bipolar cryofrequency showed extensive areas of collagen deposition in the superficial dermis, with many fibroblasts (Figure 8(A) and Figure 8(B)), small new-formed blood vessels and a large amount of new-formed collagen fibers (Figure $8(C)$ and Figure $8(D)$ ), and a few areas of edema at the dermoepidermal junction (Figure 8(E)). 


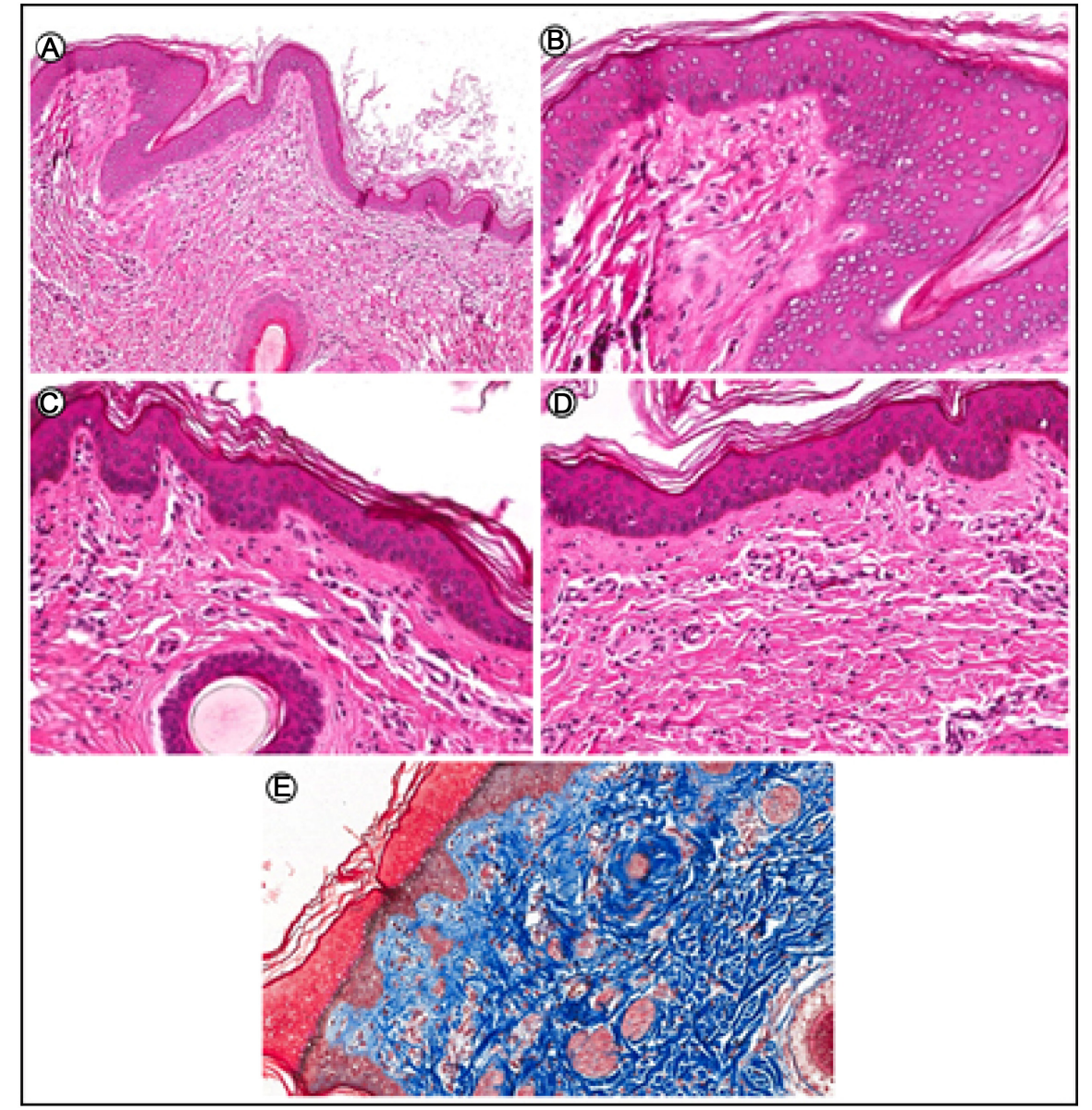

Figure 8. Collagen results with the bipolar cryofrequency. (A): Deposition of collagen in the superficial dermis. (B): Deposition of collagen in the superficial dermis. (C): Fibroblasts and small new-formed blood vessels. (D): Fibroblasts and small new-formed blood vessels. (E): Newformed collagen fibers.

\section{Discussion}

In this study, we have studied the effects of different forms of radiofrequency, cryofrequency and the association of both (cryofrequency) in the skin tissue. In the in vitro study, the temperatures presented variable values within the different depths $(0.5 \mathrm{~cm}$ and $3 \mathrm{~cm})$. In the in vivo assay, the highest and lowest temperature values were not as distant, except for the monopolar and bipolar cryofrequency measurements, in which higher temperatures were registered $(3 \mathrm{~cm}$ depth). Rossignolli (2013) [11] states that the bipolar RF energy is concentrated close to the tip of the active electrode and that it decreases rapidly with distance, and the depth of its action is up to $6 \mathrm{~mm}$. Bipolar RF has a more superficial effect when compared to the monopolar RF (up to $2 \mathrm{~mm}$ deep).

In the monopolar mode, the produced electromagnetic waves allow deep heat penetration into the tissue whereas the cooling is applied onto the surface to protect the cutaneous tissue, and depending on the exposure intensity to the cold, the cellular stress induces apoptosis, programmed cell death [12], which justifies the fat layer decrease identified in the histological analysis through in 
both monopolar radiofrequency and monopolar cryofrequency.

The monopolar cryofrequency more effective when compared to monopolar $\mathrm{RF}$ in adiposity was in this study. These findings corroborate with McDaniel et al. (2014) [12], which states that that with the association of cold to radiofrequency, the shock proteins are involved in the activation of the innate cells of the immune system, resulting which results in the infiltration of macrophages in adipose tissue by the elease of Chemokines, such as the MCP-1, which has the function of regulating the migration of phagocytic cells. Some studies [9] [13] have shown that the inflammatory response causes the release of HSP60 in adipocytes in humans due to thermal changes, inducing the release of pro-inflammatory substances and causing insulin resistance.

Nakai et al. (1992) [14] reported that most HSP genes, including HSP-27, HSP-60, HSP-70, and HSP-90, but especially HSP-70, showed stimulus resulting from thermal shock in this same context. The researchers described that HSP 90 presents a stable association form with HSP-47, which is specific for collagen. This data corroborates with the findings of this study, which showed higher amounts of collagen in monopolar cryofrequency (cryotherapy and radiofrequency) compared to the monopolar RF.

It has been demonstrated that the radiofrequency is able to cause both apoptosis and neocollagenesis and neoangiogenesis [13] [15]. In this case, a selective radiofrequency focused with different parameters was applied, however, it demonstrated the possibility of apoptosis effects in the adipose tissue. To clarify if these effects occur in cryofrequency, additional studies should be carried out to improve the scientific basis of this physical agent and to better investigate this process of cryotherapy/radiofrequency association. Long-term analysis and immunohistochemistry with specific markers of apoptosis and HSP heat shock proteins $47,70,90$ are also suggested.

\section{Conclusion}

In conclusion, we have studied the effects of radiofrequency, cryofrequency and the association of both (cryofrequency) towards the different skin tissues. It was possible to verify that in the in vitro procedure, higher temperature variation was observed, whereas in the in vivo experiment, the temperatures varied in a smaller range, except for monopolar and bipolar cryofrequency measures, which presented higher temperatures due to the body temperature of the animal and the presence of local blood circulation. It was also observed a decrease in adipose tissue with the use of the monopolar cryofrequency, and an increase in the number of collagen fibers and of blood vessels and fibroblasts. Regarding the bipolar cryofrequency, there was no positive result related to the reduction of adipose tissue, but the connective tissue presented extensive areas of collagen deposition, and a large amount of new-formed collagen fibers.

\section{Conflicts of Interest}

The authors declare that they no conflicts of interest to disclose. 


\section{References}

[1] Sun, Y., Wu, S.F., Yan, S., Shi, H.Y., Chen, D. and Chen, Y. (2009) Laser Lipolysis Used to Treat Localized Adiposis: A Preliminary Report on Experience with Asian Patients. Aesthetic Plastic Surgery, 33, 701-705. https://doi.org/10.1007/s00266-009-9375-3

[2] Fox, C.S., White, C.C., Lohman, K., Heard-Costa, N., Cohen, P., Zhang, Y., Johnson, A.D., Emilsson, V., Liu, C.T., Chen, Y.D., Taylor, K.D., Allison, M., Budoff, M., Rotter, J.I., Carr, J.J., Hoffmann, U., Ding, J., Cupples, L.A. and Liu, Y. (2012) Genome-Wide Association of Pericardial Fat Identifies a Unique Locus for Ectopic Fat. PLOS Genetics, 8, e1002705. https://doi.org/10.1371/journal.pgen.1002705

[3] De Souza Santos Ferreira, R.C. and Medrado, A.P. (2017) Criolipólise: Aplicabilidade clínica e perspectivas da terapêutica na adiposidade localizada-uma revisão sistemática. Revista Pesquisa em Fisioterapia, 7, 94. https://doi.org/10.17267/2238-2704rpf.v7i1.1229

[4] Friedmann, D.P. (2015) A Review of the Aesthetic Treatment of Abdominal Subcutaneous Adipose Tissue: Background, Implications, and Therapeutic Options. Dermatologic Surgery, 41, 18-34. https://doi.org/10.1097/DSS.0000000000000209

[5] Leichtweis, G.S., Walter, E., Feix, C.L. and Rezer, J.F.P. (2016) Procedimentos estéticos não invasivos para o tratamento da gordura localizada e a lipoaspiração. Ciência Aliment o Bras-Salão do Conhecimento do UNUUí.

[6] Simionato, E., Mohr, F. and Winkelmann, E.R. (2013) Efeitos da crioterapia no tratamento da lipodistrofia localizada-Revisão de literatura. Rev Biomotriz, 7, 90-107.

[7] Lofeu, G.M., Bartolomei, K., Brito, L.R.A. and Carvalho, A.A. (2015) Atuação da radiofrequência na gordura localizada no abdômen: Revisão de literatura. Revista da Universidade Vale do Rio Verde, 13, 571-581.

https://doi.org/10.5892/ruvrd.v13i1.2013

[8] Franco, W., Kothare, A., Ronan, S.J., Grekin, R.C. and McCalmont, T.H. (2010) Hyperthermic Injury to Adipocyte Cells by Selective Heating of Subcutaneous Fat with a Novel Radiofrequency Device: Feasibility Studies. Lasers in Surgery and Medicine, 42, 361-370. https://doi.org/10.1002/1sm.20925

[9] Inacio, R.F. (2017) Análise Comportamental Do Tratamento De Radiofrequência E Criofrequência: Revisão. Revista Saúde em Foco, 9, 248-256.

[10] Manual Body Health. Cryo-Radiofrequency. Triple Collagen Reproduction Power. http://www.bodyhealthgroup.com/?page_id=2112\&lang=en

[11] Rossignolli, M.Q. (2013) Efeitos da Eletrolipólise no Tratamento da Gordura Localizada Abdominal em Mulheres que Praticam Atividade Física: Uma Revisão da Literatura. Universidade Católica de Goias.

[12] McDaniel, D., Fritz, K., Machovcova, A. and Bernardy, J. (2014) A Focused Monopolar Radiofrequency Causes Apoptosis: A Porcine Model. Journal of Drugs in Dermatology, 13, 1336-1340.

[13] Carvalho, M.G.F., Silva, R.M.V., Mesquita Filho, J., Meyer, P.F., Ronzio, O.A., Medeiros, J.O., et al. (2011) Avaliação dos efeitos da radiofrequência no tecido conjuntivo. Revista Brasileira de Medicina, 68, 10-25.

[14] Nakai, A., Satoh, M., Hirayoshi, K. and Nagata, K. (1992) Involvement of the Stress Protein HSP47 in Procollagen Processing in the Endoplasmic Reticulum. Journal of Cell Biology, 117, 903-914. https://doi.org/10.1083/jcb.117.4.903

[15] Meyer, P.F., de Oliveira, P., Silva, F.K.B.A., da Costa, A.C.S., Pereira, C.R.A., 
Casenave, S., Valentim Silva, R.M., Araújo-Neto, L.G., Santos-Filho, S.D., Aizamaque, E., Araújo, H.G., Bernardo-Filho, M., Carvalho, M.G.F. and Soares, C.D. (2017) Radiofrequency Treatment Induces Fibroblast Growth Factor 2 Expression and Subsequently Promotes Neocollagenesis and Neoangiogenesis in the Skin Tissue. Lasers in Medical Science, 32, 1727-1736.

https://doi.org/10.1007/s10103-017-2238-2 